\title{
Response latency in immediate memory: Free number of responses vs. fixed number of responses
}

\author{
PAUL FRAISSE \\ Laboratoire de Psychologie Expérimentale et Comparée, Paris, France 75006
}

\begin{abstract}
In an immediate memory task where cards with six letters were presented tachistoscopically, a decrease in response latency inversely proportional to the number of recognized letters was found. On the other hand, when subjects had to recognize a limited number of letters, latency increased proportionally to the number of responses. These results lead to the conclusion that response elaboration is a complex process that depends on the number of responses immediately recognized and on the time spent searching for stimuli that were detected but not recognized. The time necessitated by the verification of an answer was about the same as the time necessary for the verification of the accuracy of a recognized item (about 40-50 msec).
\end{abstract}

The studies that have been conducted during the last 20 years within the framework of information processing have shown the fecundity of Donders' (1969) idea that variations in reaction time may help to analyze cognitive processes that occur between stimulation and response. In a previous study (Fraisse \& Smirnov, 1976), ${ }^{1}$ the latency of the first response was studied in an immediate memory task; the subjects were asked to recall a certain number of simple items that they had seen either simultaneously or successively for a brief duration that prevented overt or covert rehearsal. It was found, both with simultaneous tachistoscopic presentation and with successive presentation, that the latency of the first response increased proportionally to the number of items reported (R), which was itself equal to the number of items presented $(S)$ when only correct responses were taken into account $(R=S)$. This increase in the first response latency was interpreted as being due to the elaboration of responses before their emission. Once the subject begins to answer, he emits his responses at nearly constant speed.

The same study was pursued in an experiment (Fraisse, 1978a) where the number of items (letters) was varied and the latency of correct responses $(R=S)$ and of correct but incomplete responses $(R<S)$ was systematically analyzed. It was found that latency of incomplete responses was always longer than that of complete ones, and that the more incomplete the response, the longer the latency.

This finding, which had already been incidentally observed in a study on the immediate memory of geometric figures and nouns (Fraisse, 1977), suggested that latency of incomplete responses involved two durations: the duration corresponding to the elaboration of recognized stimuli and a duration corresponding to

Requests for reprints should be sent to P. Fraisse, Laboratoire de Psychologie Expérimentale, 28 rue Serpente, Paris, France 75006. the search of stimuli that had been detected but not identified. It is well established that, in tachistoscopic presentation, the subject detects the presence of stimuli that he cannot identify. This fact was explicitly verified in an experiment where, besides the immediate memory task, the subjects were submitted to a visual number-discrimination task (Fraisse, 1978a). It was shown that the number of stimuli that are detected (threshold $=7.7$ letters) is always higher than the number of stimuli that are recognized (threshold $=4.7$ letters).

In order to test the hypothesis that an increase in the latency of incomplete responses is due to the searching duration, this factor was suppressed in the present research by asking the subject to identify a defined number of stimuli smaller than the number of stimuli visually presented. In such conditions, it was predicted that latency should increase with the number of responses within the limits of immediate memory.

Latency of incomplete responses was compared in two conditions: (1) when the subject was asked to identify and recall within a set of six letters as many letters as he could (task of immediate memory), and (2) when the subject was asked to recall only a certain number of letters within a set of six.

\section{METHOD}

\section{Apparatus}

The stimuli were presented tachistoscopically (Scientific Prototype Model GB) for $150 \mathrm{msec}$. Luminance was $24 \mathrm{fL}$. The latency of the first response was measured by a vocal key that stopped a timer that was triggered when the stimulus appeared. The subject himself administered the stimulus by pressing a key when he was ready.

\section{Subjects}

Ten Psychology students (males and females) between 19 and 25 years of age participated in the experiment.

\section{Material}

The stimuli consisted of white cards on which were printed in black six letters ( $4 \mathrm{~mm}$ high and $3 \mathrm{~mm}$ wide). All the letters 
Table 1

Latency of the First Response in Milliseconds

\begin{tabular}{|c|c|c|c|c|c|c|c|c|c|c|c|c|c|c|c|c|c|c|}
\hline \multirow[b]{3}{*}{ Recall } & \multicolumn{18}{|c|}{ Number of Items in the Response } \\
\hline & \multicolumn{3}{|c|}{1} & \multicolumn{3}{|c|}{2} & \multicolumn{3}{|c|}{3} & \multicolumn{3}{|c|}{4} & \multicolumn{3}{|c|}{5} & \multicolumn{3}{|c|}{6} \\
\hline & $\mathbf{M}$ & SD & $\%$ & $\mathbf{M}$ & SD & $\%$ & $\mathbf{M}$ & SD & $\%$ & $\mathbf{M}$ & SD & $\%$ & M & SD & $\%$ & M & SD & $\%$ \\
\hline $\begin{array}{l}\text { Free } \\
\text { Fixed }\end{array}$ & 704 & 113 & 99.3 & $\begin{array}{l}974 \\
768\end{array}$ & $\begin{array}{l}188 \\
106\end{array}$ & $\begin{array}{r}3.0 \\
98.3\end{array}$ & $\begin{array}{l}926 \\
828\end{array}$ & $\begin{array}{l}101 \\
118\end{array}$ & $\begin{array}{l}28.9 \\
95.0\end{array}$ & $\begin{array}{l}891 \\
870\end{array}$ & $\begin{array}{r}89 \\
159\end{array}$ & $\begin{array}{l}39.1 \\
72.7\end{array}$ & 843 & 126 & 7.1 & 778 & 11 & 1.5 \\
\hline
\end{tabular}

Note $-M=$ interindividual mean; $S D=$ standard deviation; $\%=$ percentage of accurate responses (computed with respect to the total number of responses in the free recall condition and to the total of responses in each fixed recall condition).

of the alphabet (except, G, I, N, P, Q, W, which were omitted to diminish visual confusions) were used an equal number of times. Thirty different cards with six different letters on each were used. Letters were placed on two imaginary circles in six of eight possible locations defined in advance. The diameter of the outer circle was $30 \mathrm{~mm}$; that of the inner circle was $10 \mathrm{~mm}$ (the total area corresponded to an angle of less than $2 \mathrm{deg}$ ). The position of the six letters was varied from one card to another. Each possible location was used from 11 to 12 times. Each letter was used nine times. At the center of the card, there was a neutral area of 4-mm diam where a fixation point appeared before the presentation of the display.

\section{Procedure}

The subjects were told that the displays had six letters. The experiment lasted about $1 \mathrm{~h}$ and consisted of three phases: (1) familiarization (the subject saw the 30 cards 10 times in a free recall condition, the instructions being the same as in Phase 2; (2) free recall (the subject was asked to identify as many letters as possible and to report as rapidly as possible only those letters that he was sure of; the 30 cards were presented three times); (3) fixed recall (the subject was told that he would see six letters but would have to report only a limited number of letters as accurately and as rapidly as possible; the 30 cards were presented for each of four response conditions: The subject had first to recall one letter, then two, then three, and then four). Latency of the first response and accuracy of responses were recorded in all conditions.

\section{RESULTS}

The data analyzed here do not include response errors, that is, responses involving letters that were not on the display. In the free recall condition, all correct responses, complete or not, were analyzed $(79.6 \%$ of the total number of responses). In the fixed recall condition, only responses that were totally accurate (in content and number of items) were analyzed (91\% of the total responses).

The latency of the first response was computed for each subject, then the interindividual means and the standard deviations (see Table 1). In the free recall condition, the latency of the response linearly decreased ( $p<.005$ ) with the number of missing elements (decrement $=47 \mathrm{msec} /$ element). In the fixed recall condition, the latency linearly increased $(p<.005)$ with the number of emitted elements (increment $=56 \mathrm{msec} /$ element). This result confirms and makes clearer the previous work of Fraisse and Smirnov (1976). The increase in latency was due to the increase in the number of elements recalled by the subject when the number of elements in the stimulus was fixed. ${ }^{2}$
If the two series of results are compared, it is seen that for two responses, for example, latency was $768 \mathrm{msec}$ when the subject was asked to recall two items, and $974 \mathrm{msec}$ if he found only two items although he had detected more of them and knew that in this experiment there were six.

\section{DISCUSSION}

The previous finding (Fraisse \& Smimov, 1976) that the increase in response latency in immediate memory was explained by the elaboration of responses is confirmed by the present study. As it appears, the elaboration of responses is a complex process that does not depend only on the number of items to be accumulated before they are enumerated. The elaboration stage corresponds to an activity that Gardner (1973) describes as a series of decisions, Theois (1975) as a selection, and Schneider and Shiffrin (1977) as a control.

The present results show that latency is also increased by a searching for stimuli that are detected but not recognized, and that this searching time is proportional to the number of stimuli that are not recognized (i.e., that are omitted). This searching may be assimilated to a verification of omissions. The extra time necessitated by the verification of an omission is about the same as the time necessary for the verification of the accuracy of a recognized item.

These temporal constants are close to the values found in memory search (Sternberg, 1975) and in visual search (Schneider \& Shiffrin, 1977). Although different, the tasks used in these experiments and in the present study can be compared. A task of immediate recall of letters is comparable to a memory search if one admits that the subject has in memory the letters of the alphabet and is to verify their presence on the display. Searching for omissions would increase the latency in the same way as a negative answer requires more time than a positive answer in memory search. The second task, identifying from one to four elements, would correspond to visual search, since the subject has to recognize one or several elements among a larger set.

However, even though the two present tasks are comparable to visual search and to memory search, they do not strictly correspond to them. It is, therefore, interesting to note the similarity of temporal constants found in the different tasks. These seem to characterize the time necessary for the verification of positive responses or of responses that are omitted because of a lack of cues for recognition of the items in the present experiment.

\section{REFERENCES}

Donders, F. C. On the speed of mental processes. In W. G. Koster (Ed.), Attention and performance II. Amsterdam: North-Holland, 1969. (Reprinted from Acta Psychologica, 1969, 30.) 
Fraisse, P. La mémoire immédiate de noms et de figures géométriques. L'Année Psychologique, 1977, 77, 325-342.

FraISSE, P. La latence des réponses complètes et incomplètes en mémoire immédiate. L'Année Psychologique, 1978, 78, 39-60.(a)

FraIsSE, P. La recherche visuelle de signaux multiples. L'Année Psychologique, 1978, 78, 349-373. (b)

Fraisse, P., \& SMirnov, S. Response latency and the content of immediate memory. Bulletin of the Psychonomic Society, 1976, 8, 345-348.

GARDNER, G. I. Evidence for independent parallel channels in tachistoscopic perception. Cognitive Psychology, 1973, 4, 130-155.

SChneider, W., \& Shiffrin, R. M. Controlled and automatic human processing. I. Detection, search and attention. Psychological Review, 1977, 84, 1-66.

STERnberg, S. Memory scanning: New findings and current controversies. Quarterly Journal of Experimental Psychology, 1975, 27, 1-32.
Theios, J. The components of response latency in simple human information. In P. M. A. Rabbitt \& S. Dornic (Eds.), Attention and performance V. New York: Academic Press, 1975.

\section{NOTES}

1. Fraisse and Smirnov (1976) wrote that in successive presentation, the latency of the first response was proportional to the number of responses only when more than three items were reported; this statement was wrong. A more detailed analysis has shown that equations of regression are about the same in simultaneous and successive presentations [in simultaneous presentation, $T L(\mathrm{msec})=672+70 \mathrm{n}(\mathrm{p}<.005)$; in successive presentation, $\mathrm{TL}(\mathrm{msec})=704+50 \mathrm{n}(\mathrm{p}<.005)]$.

2. Latency also increases with the number of elements in the display (Fraisse, 1978b).

(Received for publication November 20, 1978.) 